\title{
Article \\ Controlled Release of Zinc from Soy Protein-Based Matrices to Plants
}

\author{
Mercedes Jiménez-Rosado*(D), Victor Perez-Puyana, Antonio Guerrero (D) and Alberto Romero (D) \\ Departamento de Ingeniería Química, Facultad de Química, Escuela Politécnica Superior, Universidad de Sevilla, \\ 41012 Sevilla, Spain; vperez11@us.es (V.P.-P.); aguerrero@us.es (A.G.); alromero@us.es (A.R.) \\ * Correspondence: mjimenez42@us.es
}

check for updates

Citation: Jiménez-Rosado, M.

Perez-Puyana, V.; Guerrero, A.;

Romero, A. Controlled Release of Zinc from Soy Protein-Based Matrices to Plants. Agronomy 2021, 11, 580. https://doi.org/10.3390/ agronomy 11030580

Academic Editor: Borjana Arsova

Received: 12 February 2021

Accepted: 17 March 2021

Published: 19 March 2021

Publisher's Note: MDPI stays neutral with regard to jurisdictional claims in published maps and institutional affiliations.

Copyright: (c) 2021 by the authors. Licensee MDPI, Basel, Switzerland. This article is an open access article distributed under the terms and conditions of the Creative Commons Attribution (CC BY) license (https:// creativecommons.org/licenses/by/ $4.0 /)$.

\begin{abstract}
Controlled release systems are increasing their presence on the market. However, their use is not generating a great impact on horticultural production, mainly due to their price, which makes crop production more expensive. This work proposes a cheaper alternative for the manufacture of these devices. Thus, an agri-food byproduct (soy protein isolate) and a thermomechanical processing were used to create devices (matrices) that can compete in price with the use of conventional fertilizers $(0.50-2.00 € / \mathrm{kg})$. First, different processing methods were evaluated to obtain the matrix with the most optimal mechanical, functional (zinc and water retention/release, biodegradability) and morphological (zinc distribution) properties for the supply of zinc (micronutrient). This was achieved by incorporating an ethanol immersion step into the processing to remove the plasticizer before its use in horticulture. Finally, the efficiency of these matrices was verified in crops (lettuce and peppers), improving up to $60 \%$ the assimilation of zinc by plants that conventional fertilization achieves. In addition, these matrices allow a 33\% reduction in the water used during cultivation. This work has opened a new possibility of creating more efficient devices for the incorporation of fertilizers into crops, also having an affordable price for industrial use.
\end{abstract}

Keywords: controlled release; matrices; micronutrient; zinc; crop studies

\section{Introduction}

Nowadays, horticulture is a crucial sector, as it can provide products that contribute to a healthier lifestyle. This has led its production to increase by $22.9 \%$ in the last 10 years [1]. Unfortunately, such an increase involves the overexploitation of the farmland [2]. Soils have been excessively degraded, since they do not have enough time between each harvest to regenerate their nutrients. This is due to the fact that the cultivation soil is limited, so they are used for different crops in intensive horticulture, sowing seeds when the previous harvest is recollected, without leaving enough time for the soil to breathe [3]. This fact, together with the low short-term efficiency of other solutions (i.e., fallow or conservation tillage), has led to excessive use of fertilizers [4]. Fertilizers are any organic or inorganic substance which, incorporated into the soil, provides the necessary nutrients for the development of crops [5]. Their advantages include their speed to counteract the deficiencies of the farmland and their low cost [6]. However, they also may generate serious problems. The most serious problem is their filtration to the subsoil and groundwater, which contaminate them with an excess of nitrates and phosphates, being dangerous for the environment and humans. This filtration is due to the low assimilation of fertilizers by plants, which only captures a small part of the fertilizers incorporated in the soil. In addition, this low assimilation generates that more quantity of fertilizers must be incorporated into the soil during the crop growth, which results in a higher production cost [7].

Within this sector, Andalusia (southern region of Spain) has $41.3 \%$ of its surface occupied by farmland, which is equivalent to $4,591,460$ ha, with a production of $9,300,363$ tons in 2018, generating $9.18 \%$ of Andalusian employment. This is due to its climate, ideal for 
cultivation throughout the year. Besides, $62 \%$ of the products grown in this territory have quality certification [8]. It has become the main exporter of the European community, being among the top 10 in the world [9]. Furthermore, 4,305,253 tons of fruit and vegetables were exported in 2018, which is equivalent to 5385 million euros. Its main products are peppers, tomatoes, cucumbers, squashes and strawberries, with Germany, France, Italy and United Kingdom being their main buyers [10]. Andalusian farmland is clayey with ancient limestone materials, and it is usually deficient in micronutrients such as manganese, iron, copper and zinc, with the scarcity of the latter being the most problematic of all [11]. Zinc is the element that activates the enzymes responsible for the synthesis of certain proteins, being also important in the formation of chlorophyll and some carbohydrates, as well as in the conversion of starches to sugar. In addition, its presence in the foliar tissue is essential in the formation of auxins, which contribute to the regulation of the development and elongation of the stem [12]. Its deficiency can decrease the production of the crop by over $50 \%$, thus it is vital to detect it in time and counteract it, for which zinc sulfate is normally used [13].

The deficiency of nutrients and the high consumption of fertilizers have generated a new research field focused on the study of more effective fertilization methods [14-16]. These investigations do not only focus on reducing the number of fertilizers used but also search for competitive fertilization techniques that do not make the final product more expensive, which is still a challenge. Among them, the use of controlled release systems is gaining special interest, since they allow adjusting the supply of nutrients to the needs of the crops, thus improving efficiency and reducing contamination $[17,18]$. In this context, Merino et al. (2019) [19] used corn starch films to incorporate sodium to crops. Mesias et al. (2019) [20] and Kartini et al. [21] incorporated NPK (nitrogen, phosphorus and potassium) fertilizers in chitosan/alginate capsules and carboxymethyl cellulose bioplastics, respectively. However, the raw materials and techniques used to manufacture these systems have great scalability problems and, therefore, they cannot compete with conventional fertilization (their price ranges from 1.50 to $22.00 € / \mathrm{kg}$ compared to $0.75-3.00 € / \mathrm{kg}$ of conventional fertilizers). In recent years, cheaper raw materials that can be processed by easier and more scalable methods have been investigated for their use in this application [22]. In this way, the use of agri-food waste or byproducts, such as soy protein, has gained special interest for the fabrication of these controlled release devices, not only due to their low price, but also because they can be processed by the same methods used by conventional plastics, which makes them a competitive alternative to conventional fertilizers $(0.50-2.00 € / \mathrm{kg})$ [23-25]. However, the studies carried out so far have not succeeded in producing a bioplastic matrix that provides adequate release kinetics for use in horticulture.

The main objective of this work was the development of soy protein-based matrices with zinc sulfate incorporated with the adequate properties to efficiently supply zinc to crops. For this, different processing methods were evaluated to produce matrices with sustainable zinc retention and distribution. In addition, mechanical properties (to evaluate their behavior during storage and distribution) and water uptake capacity (added value) were also studied. Finally, the use of these matrices for the fertilization of lettuce and peppers was compared with conventional fertilizers.

\section{Materials and Methods}

\subsection{Materials}

Matrices were composed of soy protein isolate (SPI), which was supplied by Protein Technologies International (Ieper, Belgium), with $91 \mathrm{wt} . \%$ protein. This raw material was provided from the industrial production of soybean oil, being a byproduct of this process. Besides, glycerol (Gly), which was provided by Panreac Química S.A. (Barcelona, Spain), was used as plasticizer.

Zinc was incorporated in the matrix as a salt, specifically zinc sulfate monohydrate $\left(\mathrm{ZnSO}_{4} \cdot \mathrm{H}_{2} \mathrm{O}\right)$. This salt was selected due to its common use in horticulture to supply zinc to crops [26]. It was also provided by Panreac Química S.A. 
The soil used in this work was supplied by farmers from zinc-deficient farmland in the South Highlands of Seville (Andalusia, Spain). The soil analysis indicates that the $\mathrm{pH}$ of the farmland was 8 . This $\mathrm{pH}$ is slightly alkaline, indicating that there was possibly an excess of calcium and magnesium in the soil. Normally, to counteract this, substances that contain sulfur are incorporated in order for the thio-bacteria present in the soil to convert it to sulfuric acid [27]. On the other hand, its salinity was represented by a conductivity of $561 \mu \mathrm{S} / \mathrm{cm}$. Its carbonate content is lower than 15\% (as it does not produce effervescence in contact with hydrochloric acid), which does not generate problems for the cultivation of any type of crop [28]. The organic matter was $1.5 \%$ in this soil, which is slightly higher than those found in this area $(<1 \%)$ [8]. However, this increase could be due to the large rainfall that occurred before the soil was collected, which generated a more humid environment than usual in this territory. Nevertheless, this increase in the organic matter does not pose problems for crop growth.

Table 1 shows the nutrients present in the soil. All the nutrients were within tolerable limits [13], except for the excessive amount of calcium, as expected with the $\mathrm{pH}$ measurement, and the poor content of zinc ( $<15 \mathrm{mg} / \mathrm{kg}$ soil). This deficiency is usual in soils with a $\mathrm{pH}$ above 7 [29]. Furthermore, the soil was not contaminated by heavy metals $(\mathrm{Pb})$ nor by pesticides (As), as they were found in amounts lower than $5 \mathrm{mg} / \mathrm{kg}$ soil [30].

Table 1. Chemical composition of the studied soil.

\begin{tabular}{ccc}
\hline Element & Amount in Soil (mg/kg Soil) & $\begin{array}{c}\text { Ideal Conditions } \\
\text { (mg/kg Soil) }\end{array}$ \\
\hline $\mathrm{P}$ & 2841 & $2600-3500$ \\
$\mathrm{NO}_{3}^{-}$ & 49 & $40-350$ \\
$\mathrm{NH}_{4}^{+}$ & 47 & $20-70$ \\
$\mathrm{Ca}$ & 177,517 & $2200-5000$ \\
$\mathrm{Mg}$ & 5387 & $730-1700$ \\
$\mathrm{~K}$ & 3804 & $2000-4000$ \\
$\mathrm{Na}$ & 797 & $80-340$ \\
$\mathrm{Cu}$ & 22 & $20-50$ \\
$\mathrm{Mn}$ & 218 & $200-800$ \\
$\mathrm{Fe}$ & 9158 & $100-10,000$ \\
$\mathrm{Zn}$ & 7 & $15-180$ \\
$\mathrm{~S}$ & 789 & $500-800$ \\
$\mathrm{Cr}$ & 13 & $10-60$ \\
$\mathrm{Ni}$ & 9 & $10-35$ \\
$\mathrm{~Pb}$ & 3 & $<5$ \\
$\mathrm{As}$ & 4 & $<5$ \\
\hline
\end{tabular}

Finally, it was determined that the soil texture was clayey (according to USDA classification [31]), with $62 \%$ clay and $38 \%$ sand. These soils tend to retain large amounts of water-the water capacity of the soil is approximately $26 \%$.

The crops grown were lettuce (Lactuca sativa) and Italian sweet pepper (Capsicum annuum). Moreover, grass (Cynodon dactylon) was used to control germination. They were provided by Ramiro Arnedo Semillas (Spain).

\subsection{Matrix Processing}

The matrices were processed using a five-stage process (mixing + injection molding + dehydrothermal treatment + immersion + freeze-drying), which has already been studied [32]. Three variants of the process were studied to evaluate which one generates the most suitable micronutrient incorporation. In this way, the stage at which the salt was incorporated and the immersion solvent were changed in each protocol, as shown in Table 2. 
Table 2. Raw materials, micronutrient (MN) incorporation and immersion solvent of the different protocols used to produce matrices with zinc incorporated.

\begin{tabular}{|c|c|c|c|c|c|}
\hline \multirow{2}{*}{ Protocol } & \multicolumn{3}{|c|}{ Raw Materials in Mixing (\%) } & \multirow{2}{*}{$\begin{array}{l}\text { Stage of } \mathrm{MN} \\
\text { Incorporation }\end{array}$} & \multirow{2}{*}{ Immersion Solvent } \\
\hline & SPI & Gly & $\mathrm{ZnSO}_{4} \cdot \mathrm{H}_{2} \mathrm{O}$ & & \\
\hline $\mathrm{A}$ & 45 & 45 & 10 & Mixing & Water \\
\hline $\mathrm{E}$ & 45 & 45 & 10 & Mixing & Ethanol \\
\hline S & 50 & 50 & 0 & Immersion & $\begin{array}{l}\text { Saturated zinc sulfate } \\
\text { salt solution }(1 \mathrm{~g} / \mathrm{mL})\end{array}$ \\
\hline
\end{tabular}

The processing conditions were maintained. Firstly, the raw materials were homogenized in the mixing stage, using the proportions shown in Table 2. To this end, the raw materials were introduced in a Polylab QC mixer (ThermoHaake, Karlsruhe, Germany), mixing them for $10 \mathrm{~min}$ at $50 \mathrm{rpm}$ under adiabatic conditions. The obtained dough-like blends were injection molded to obtain bioplastic matrices in a MiniJet Piston Injection Molding System II (ThermoHaake, Karlsruhe, Germany). The parameters used in this stage, following previous studies [25], were cylinder and mold temperatures of 40 and $90^{\circ} \mathrm{C}$, respectively, and injection and holding pressures of $600 \mathrm{bar}(20 \mathrm{~s})$ and $200 \mathrm{bar}(300 \mathrm{~s})$, respectively. After this stage, the bioplastics were reinforced using a dehydrothermal treatment at $50^{\circ} \mathrm{C}$ in a conventional oven (Memmert, Schwabach, Germany) for $24 \mathrm{~h}$.

Once the bioplastic matrix has been reinforced, glycerol must be removed from the matrix. In this way, each system was submerged in its corresponding solvent, according to Table 2, for $24 \mathrm{~h}$. Subsequently, the different swollen matrices were frozen at $-40{ }^{\circ} \mathrm{C}$ for $2 \mathrm{~h}$ and subjected to solvent sublimation in a LyoQuest freeze-dryer (Telstar, Madrid, Spain) at $-80{ }^{\circ} \mathrm{C}$ and $0.1 \mathrm{mbar}$ for $24 \mathrm{~h}$.

\subsection{Characterization of Matrices}

\subsubsection{Mechanical Properties}

Matrices need a certain mechanical resistance to maintain their structural integrity over transportation and storage. Thus, dynamic sweep tests were performed to study the response of the matrices to compressional deformations. The tests were carried out in a dynamic-mechanical analyzer RSA3 (TA Instrument, New Castle, DE, USA) with a parallel plate geometry (dia: $8 \mathrm{~mm}$ ). The analyses were performed between 0.02 and $20 \mathrm{~Hz}$ at room temperature $\left(25 \pm 2{ }^{\circ} \mathrm{C}\right)$, using $65 \%$ of the critical strain (previously calculated, results not shown). In this way, the elastic ( $\left.E^{\prime}\right)$ and viscous ( $\left.E^{\prime \prime}\right)$ moduli were evaluated along the frequency range.

\subsubsection{Zinc Loading}

The main characteristic of these matrices is their encapsulated zinc content, which can be released. In order to evaluate the zinc loading of each matrix, inductively coupled plasma-atomic emission spectroscopy (ICP-AES) analyses were carried out. To this end, the samples were firstly digested with acids and then dissociated at a temperature of $6000 \mathrm{~K}$ in an ICP SpectroBlue TI (Spectro, Kleve, Germany) to obtain the characteristic wavelengths of each element.

The interaction between zinc and the biopolymeric chains were analyzed by Raman spectrometry, introducing $300 \mathrm{~g} / \mathrm{mm}$ of the sample in a LabRAM spectrometer (Horiba, Kyoto, Japan), where bond vibrations were measured at $785 \mathrm{~nm}$ with an acquisition time of $4 \mathrm{~s} /$ accumulation and a hole of $100 \mu \mathrm{m}$.

\subsubsection{Zinc Distribution}

The way in which zinc is distributed into the matrix influences the kinetics of its release. Therefore, the distribution of elemental concentration was analyzed in the surface and inside of each matrix, using a scanning electron microscope (JEOL 6460LV, Pleasanton, CA, USA) with a complement coupled to perform energy-dispersive X-ray analyses (EDXA). 


\subsubsection{Zinc Release in Water}

Cong et al. (2010) [33] and Essawy et al. (2016) [34] determined an easy protocol to control the release of fertilizers from different matrices. The matrices were submerged in $300 \mathrm{~mL}$ of distilled water, controlling the release of zinc by measuring the conductivity (ECmetro BASIC 30, Spain). The release is estimated to be completed when the conductivity remains constant for more than $1 \mathrm{~h}$.

\subsubsection{Water Uptake Capacity (WUC)}

An added value of these matrices is the release of water to crops. Water uptake capacity tests were carried out to evaluate this property. In this context, the matrices were immersed in $300 \mathrm{~mL}$ of distilled water for $24 \mathrm{~h}$, according to the ASTM D570-98 standard [35]. The water uptake capacity (WUC) was calculated using Equation (1):

$$
\operatorname{WUC}(\%)=\frac{a-b}{b} \cdot 100
$$

where $a$ is the weight of the system after the immersion step and $b$ is the weight of the system after water immersion and dry treatment by freeze-drying.

\subsection{Plant Study}

\subsubsection{Zinc Release in Soil}

The analysis of micronutrient release in soils provides a closer estimation of the use of matrices in horticulture. For its evaluation, the matrices were buried in the soil (previously characterized) in cylinder glass tubes of $40 \times 2 \mathrm{~cm}^{2}$ open at the bottom. To simulate an intensive irrigation of $20 \mathrm{~L}$ water $/ \mathrm{m}^{2}$, the tubes were irrigated with $20 \mathrm{~mL}$ of water every $24 \mathrm{~h}$. A scheme of the experimental set-up can be observed in Figure S1. Zinc release was estimated by measuring the conductivity of the leachate using a BASIC 30 EC-meter until no signal was detected in the leachate. It is worth mentioning that a blank was made without incorporated matrices in the soil to compare the conductivity caused by the soil salinity.

\subsubsection{Matrix Biodegradability}

The biodegradability of the different matrices was evaluated by burying the matrices in the soil. At least three matrices $\left(60 \times 10 \times 1 \mathrm{~mm}^{3}\right)$ of each protocol were unearthed at different days to be visually evaluated, taking pictures. Finally, the total biodegradation time was estimated as the test days after which the matrix could not be unearthed.

\subsubsection{Crop Evaluation}

Finally, the matrices were evaluated in their use as fertilizers. To this end, two types of crops were used: one with fast germination and growth (lettuce) and another one with fast germination and slow growth (Italian sweet pepper). A positive control (with conventional fertilization of $40 \mathrm{mg} \mathrm{ZnSO} 4 \cdot \mathrm{H}_{2} \mathrm{O}$ every 7 days), a negative control (without fertilization) and systems with the different matrices were carried out after germination of the crops. For these studies, four plants of each crop were tested with each fertilizer (positive, methods A, $\mathrm{E}$ and $\mathrm{S}$ and negative fertilization). The matrices were buried with each plant at $2 \mathrm{~cm}$ to the left of its roots. The evaluation of crops was performed by visual observation of the defect found in the plants, as well as their height and foliage. In addition, the different crops were analyzed by ICP-AES to evaluate the amount of zinc that they had assimilated and its availability as a zinc supply for people. On the other hand, a germination study was carried out with grass seeds to evaluate the influence of the matrices during germination.

In addition, the water used for irrigation was controlled to determine the amount of water necessary for the growth of each plant. This parameter was determined as added value of the matrices. To calculate the water retention by the matrices, the total amount of water from the planting day to harvest day was registered for each plant. 


\subsection{Statistical Analysis}

At least three replicates were carried out for each measurement. Statistical analyses were performed with $t$ tests, evaluating the variance of the measurements $(p<0.05)$. These tests were carried out using SPSS 18 (Windows). The results were represented as mean values with standard deviations.

\section{Results and Discussion}

\subsection{Characterization of Matrices}

\subsubsection{Mechanical Properties}

Figure 1 shows the frequency sweep tests of the matrices processed by the different protocols. Regardless of the process used, the frequency exerts a very slight influence on the compressional elastic modulus (i.e., $\mathrm{E}^{\prime} \propto \omega^{\mathrm{n}}$, with the power-law exponent, $\mathrm{n}$, ranging between 0.03 and 0.06 ), not leading to any significant modification of the compressional viscous modulus $\left(\mathrm{E}^{\prime \prime}\right)$. In addition, the elastic modulus was always one order of magnitude above the viscous modulus. This behavior shows the predominant solid character of these matrices, facilitating their transportation and storage without being damaged. These results are similar to others found in the literature, where soy protein-based bioplastics present solid character [36], confirming that the samples show a proper mechanical stability for the three processes used.

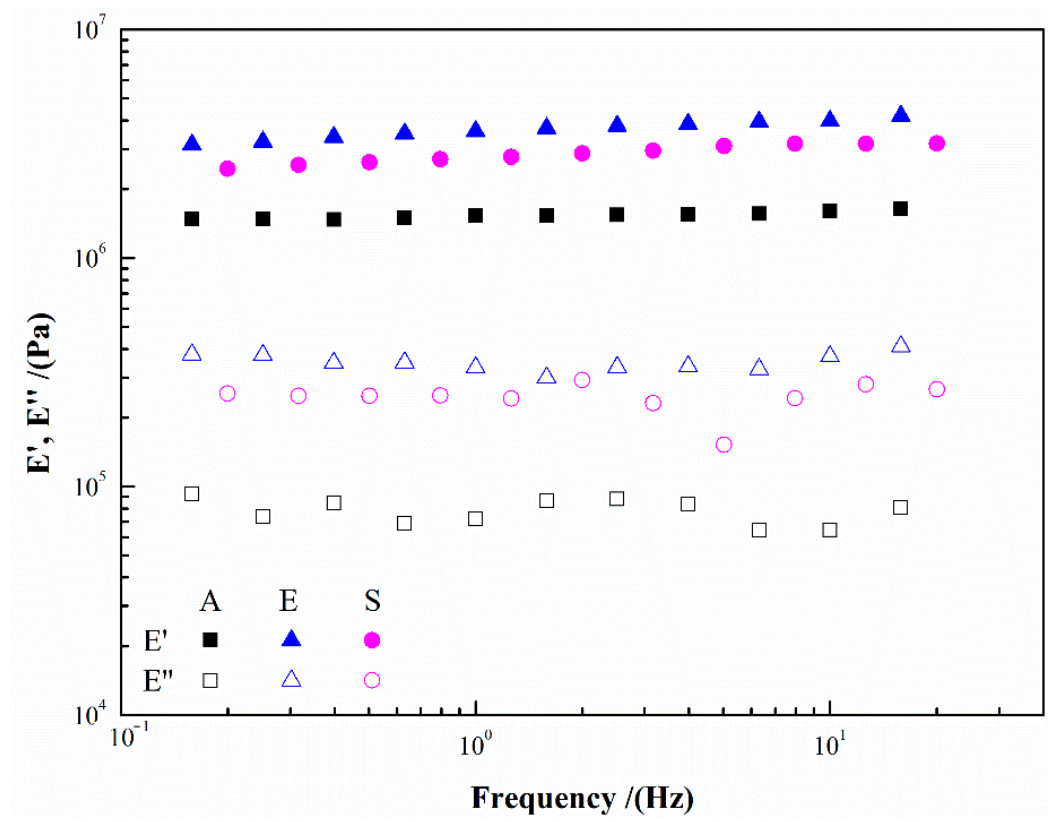

Figure 1. Elastic $\left(E^{\prime}\right)$ and viscous $\left(E^{\prime \prime}\right)$ moduli obtained in frequency sweep tests of the matrices processed by the different protocols.

On the other hand, the use of different protocols to process the matrices generated differences in the moduli values. In this context, the lowest value was obtained for the matrix processed using an immersion stage in water (A), while the highest value was obtained for the matrix processed using ethanol for the immersion stage (E). This behavior could be due to the greater material loss during immersion generated by salt and soy protein solubility in water, leading to more brittle matrices. Ethanol does not produce this solubilization, allowing high values in both elastic and viscous moduli. These results are in line with those of previous research, where the drop in the elastic modulus of protein-based matrices after immersion in water has already been demonstrated [37]. 


\subsubsection{Zinc Loading}

The amount of zinc $\left(\mathrm{Zn}^{2+}\right)$ and sulfate $\left(\mathrm{SO}_{4}{ }^{2-}\right)$ present in the different matrices is shown in Table 3. The protocol used in the processing of matrices is determinant in the amount of micronutrient incorporated in the matrix. Protocol A is the one that incorporates the least amount of zinc and sulfate in the matrix. This behavior is due to the high solubility of $\mathrm{ZnSO}_{4} \cdot \mathrm{H}_{2} \mathrm{O}$ in water, passing to the medium during immersion. However, it can be observed that some zinc is retained in the matrix (4.81 of $25.2 \mathrm{mg}$ presented in the bioplastic before the immersion), which could be caused by the negative charges of protein chains, since the $\mathrm{pH}$ of the matrix (6.5-7, approximately) was higher than its isoelectric point (5.5), generating attractive interactions with the zinc ions. This behavior has already been registered in previous works, where ionic salts (i.e., sulfate, persulfate, chloride) allow better micronutrient retention than nonionic or insoluble salts (i.e., EDTA, carbonate) [36,37].

Table 3. $\mathrm{Zinc}\left(\mathrm{Zn}^{2+}\right)$ and sulfate $\left(\mathrm{SO}_{4}{ }^{2-}\right)$ content and distribution in the matrices processed by the different protocols. Different letters mean significant differences.

\begin{tabular}{ccccccc}
\hline & \multicolumn{2}{c}{ ICP-AES } & \multicolumn{3}{c}{ EDXA } \\
\cline { 2 - 6 } Protocol & \multirow{2}{*}{$\mathbf{Z n}^{2+}(\mathbf{m g})$} & $\mathbf{S O}_{4} \mathbf{2}^{-}(\mathbf{m g})$ & \multicolumn{2}{c}{ Surface } & \multicolumn{2}{c}{ Inside } \\
\cline { 3 - 7 } & & & $\mathbf{Z n ~ ( \% )}$ & $\mathbf{S ~ ( \% )}$ & $\mathbf{Z n ~ ( \% )}$ & $\mathbf{S ~ ( \% )}$ \\
\hline $\mathrm{A}$ & 4.81 & 0 & $54^{\mathrm{a}}$ & - & $46^{\mathrm{c}}$ & - \\
$\mathrm{E}$ & 15.3 & 22.5 & $52^{\mathrm{a}}$ & $47^{\mathrm{A}}$ & $48^{\mathrm{ac}}$ & $53^{\mathrm{A}}$ \\
$\mathrm{S}$ & 28.1 & 41.4 & $58^{\mathrm{b}}$ & $65^{\mathrm{B}}$ & $42^{\mathrm{d}}$ & $35^{\mathrm{C}}$ \\
\hline
\end{tabular}

Method E corrects the problem of the high solubility of $\mathrm{ZnSO}_{4} \cdot \mathrm{H}_{2} \mathrm{O}$ found in method A, by replacing water with ethanol as the immersion medium, where it is insoluble. In this way, the retention of zinc into the matrix increases from $19 \%$ of the total amount added for matrix A to $60 \%$ achieved for matrix E, leading to a threefold amount of micronutrient load within the matrix. Moreover, the change in the micronutrient incorporation produced a greater load of it in the matrix $S$, attributed to the greater amount of zinc to which the matrix was exposed with this protocol. Thus, the amount of salt incorporated into the final matrix $\mathrm{S}$ was even higher than the amount initially added for the protocol used for matrices $\mathrm{A}$ and $\mathrm{E}$.

It is worth mentioning that, unlike in the case of protocol A, there is not any preferential retention of zinc cations over sulfate anions nor in protocol $\mathrm{E}$, where the salt remained undissociated, nor in protocol S, where the ions are incorporate from a saturated medium. This reaffirms the prevalence of electrical interactions between zinc ions and the protein in protocol A. Raman spectroscopy was used to confirm these interactions. Figure 2 shows the spectroscopic profile of a matrix without zinc and another one with it. The incorporation of zinc generates peaks at 240 and $260 \mathrm{~cm}^{-1}$, approximately, in the spectrum (indicated in Figure 2), which correspond to the interaction of zinc with functional groups of the protein, creating a metalloprotein, as its predicted by Torreggiani et al. with their zinc-protein complex [38]. 


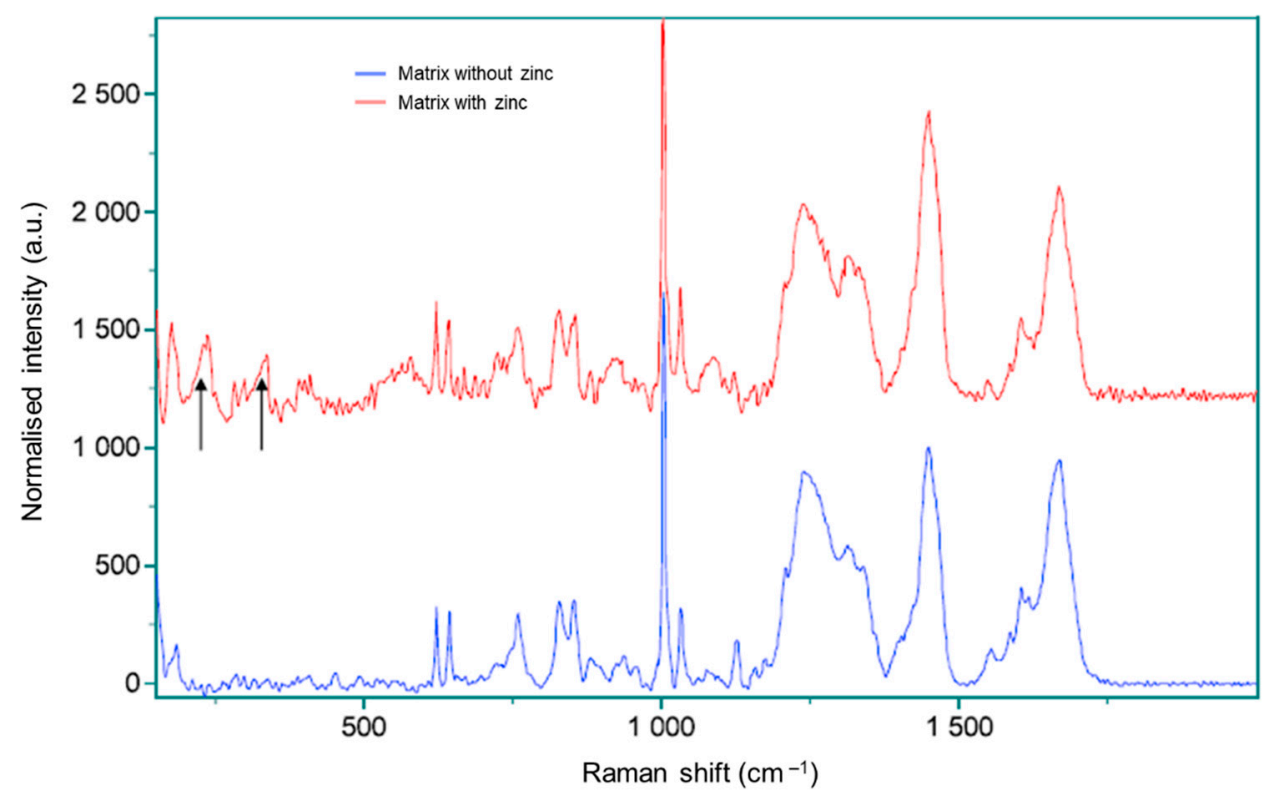

Figure 2. Raman profile of a matrix without zinc and another with zinc incorporated.

\subsubsection{Zinc Distribution}

Table 3 also shows the zinc distribution measured by EDXA. There was a homogeneous distribution when zinc was incorporated in the mixing step (protocol A and E), which was more evident when ethanol was used as the immersion solvent. However, it seems that the amount of zinc tends to be higher on the surface than inside the matrix. This could be due to the penetration of the solvent into the matrix, which drags the zinc from inside out, leaving an increasing concentration gradient from the inside of the matrix towards its surface. Since ethanol is less related to the salt used to incorporate zinc than water, its gradient is less enhanced, hence its greater homogeneity. Interestingly, there were no significant differences neither in zinc nor in sulfur content on the surface and inside of the matrix processed by protocol $\mathrm{E}$. This emphasizes the null solubility of $\mathrm{ZnSO}_{4} \cdot \mathrm{H}_{2} \mathrm{O}$ in ethanol, which seems to be unable to dissociate the salt. The ions did not generate enough attractive or repulsive electronic forces with the matrix charges, which could facilitate the heterogeneous dispersion of the components. This low solubility of $\mathrm{ZnSO}_{4} \cdot \mathrm{H}_{2} \mathrm{O}$ in ethanol has already been reported in previous works, where the solubility of this salt in different solvent was evaluated [39].

The change in the zinc incorporation from mixing (protocol $\mathrm{A}$ and $\mathrm{E}$ ) to immersion stage (protocol S) led to an apparent more significant gradient of zinc and sulfur concentrations between the surface and the inside of the matrix. In this case, both ions entered the matrix due to the difference in concentrations between the solvent (saturated in salt) and the matrix. There was a diffusion from the solvent to the surface of the matrix and from this surface to the interior of the matrix until equilibrium is reached. In addition, other effects such as solvent penetration when removing glycerol, osmotic pressure or matrix hydrofility also act during the salt penetration. In this way, since the surface is more accessible, the content in zinc and sulfur was higher in this part of the matrix. It is worth mentioning that the gradient was more significant in sulfur content than in zinc. This behavior could be induced by the repulsion forces previously mentioned between sulfate ions and protein charges, which hinder the infiltration of sulfate into the matrix, being more superficial.

\subsubsection{Zinc Release in Water}

The zinc release of the different matrices in water, measured by the change in the specific conductivity $(K)$, can be observed in Figure 3. All the matrices presented a release prolonged in time, indicating their ability to release zinc in a controlled manner. However, the speed of this release varied depending on the protocol used. 


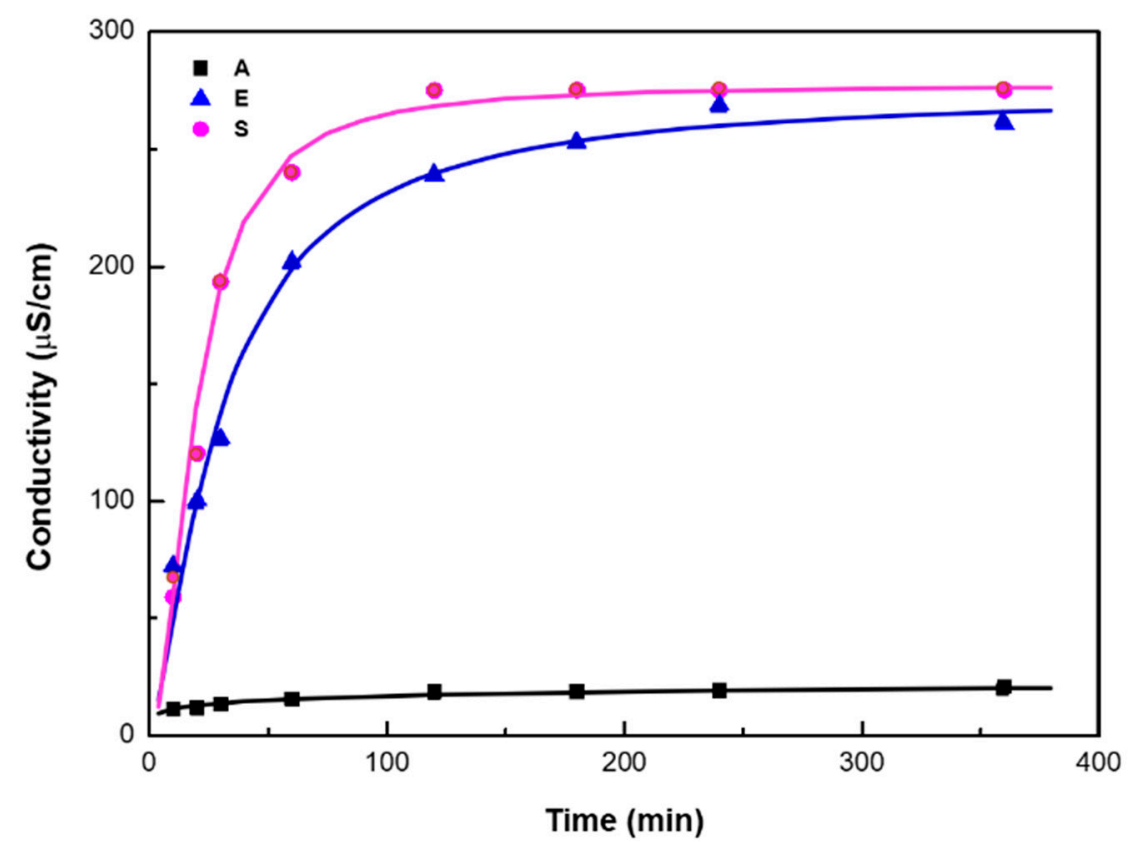

Figure 3. Micronutrient release study of the different matrices in water: accumulation of conductivity with time.

The release kinetics fit well with the following asymptotic equation for the three matrices:

$$
K=\frac{K_{\infty}}{1+\left(\frac{t_{1 / 2}}{t}\right)^{m}}
$$

where $K_{\infty}$ is the specific conductivity at infinite time, $t_{1 / 2}$ is the half release time (i.e., the time at which the specific conductivity reaches half the value of $\left.K_{\infty}\right)$ and $m$ is a dimensionless parameter which represents the power-law exponent for the initial release stage (i.e., if $t \ll t_{1 / 2}$ Equation (2) reduces to a power-law relationship, $\left.K \propto t^{m}\right)$.

The different parameters obtained for each matrix are observed in Table 4. The matrix processed by protocol A only contains a low amount of zinc but it displays a slow release, with a moderate power-law index $(m=0.27)$ and a half release time of almost $3 \mathrm{~h}$. The release kinetics for protocols $\mathrm{E}$ and $\mathrm{S}$ is characterized by two well-marked stages: (i) A faster release at the beginning, represented by a power-law equation with a high slope in conductivity $(m>1)$, with half time values of 30 and $20 \mathrm{~min}$, respectively (ii) this kinetics is followed by a region with a much slower rate which tends to a constant value at which no further release takes place. The values of parameter $m$ presented by both systems (E and S) were different, possibly due to the difference in the zinc distribution of the matrices. The greater the amount of zinc present on the surface of the matrix, the easier the zinc release and, consequently, the faster its release. Previous articles already anticipated the importance of the distribution of the desired element in the matrix for its release, estimating that a homogeneous distribution is better for the correct control of the release of fertilizers [40,41].

Table 4. Release kinetics parameters of the different matrices.

\begin{tabular}{cccc}
\hline Protocol & $\boldsymbol{\kappa}_{\infty}(\boldsymbol{\mu S} / \mathbf{c m})$ & $\boldsymbol{t}_{1 / 2}(\mathbf{m i n})$ & $\boldsymbol{m}(-)$ \\
\hline $\mathrm{A}$ & 37.0 & 177 & 0.27 \\
$\mathrm{E}$ & 274 & 30.0 & 1.4 \\
$\mathrm{~S}$ & 277 & 19.9 & 2 \\
\hline
\end{tabular}

The kinetics of this study allow predicting that the matrices will have a controlled release during their use in soils. So, its study in soils is viable. 


\subsubsection{Water Uptake Capacity}

Figure 4 shows the water uptake capacity of the matrices processed by the different protocols. This capacity depends not only on how the micronutrient has been incorporated but also on the amount of micronutrient load and its distribution in the matrix. Protocols A and $\mathrm{E}$ incorporate the micronutrient in the same stage (mixing), although the water uptake capacity of the matrix processed by protocol $\mathrm{E}$ was lower. This could be explained by the higher amount of salt present in this matrix, which prevents it from swelling during absorption due to electrostatic forces [42-44]. However, the matrix processed by protocol S was the one that retained the largest amount of zinc, also presenting better water uptake capacity than the matrix processed by protocol $\mathrm{E}$. This behavior is the possible cause of the micronutrient distribution. In this sense, zinc and sulfate ions are quickly transferred to the water, leaving a greater number of free pores that can be filled by water. On the other hand, the greater ionization in $\mathrm{ZnSO}_{4} \cdot \mathrm{H}_{2} \mathrm{O}$ during the processing of the matrices by protocols $\mathrm{A}$ and $\mathrm{S}$, possibly caused a lower electrostatic charge during the absorption of the final matrices, allowing them to increase their volume to capture and retain water.

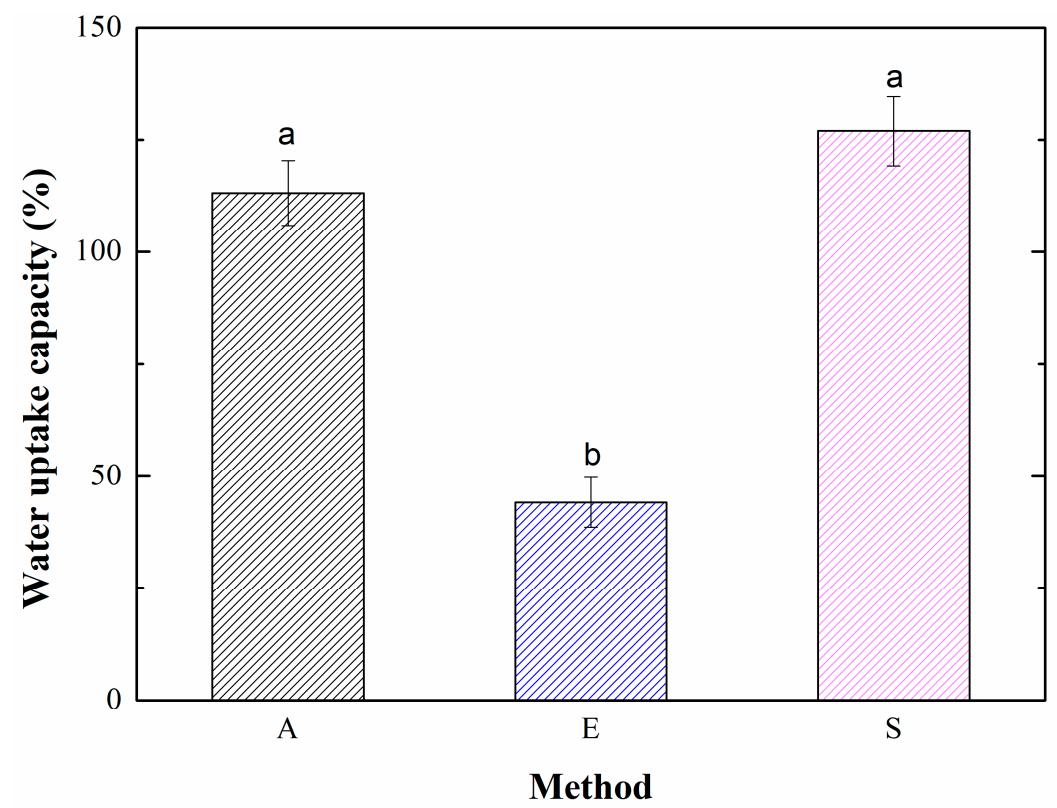

Figure 4. Water uptake capacity of the matrices processed by the different protocols. Different letters mean significant differences.

The water uptake capacity of these matrices is lower than that shown in other materials intended for this purpose. For example, Cuadri et al. (2016) obtained soy materials with a absorbent capacity of up to 3000\% [45] and Álvarez-Castillo et al. (2020) obtained similar values with plasma porcine protein-based materials [46]. However, the matrices presented in this work present this ability as a secondary characteristic. This water uptake capacity allows the reduction of irrigation by up to $33 \%$, which is an added value to these matrices.

\subsection{Plant Study}

\subsubsection{Zinc Release in Soil}

Figure 5 shows the measurements taken from the leachates in the soil release studies. These studies show the same trend already observed in water, after an induction time: all systems had a controlled release, which was faster at the beginning and slowed down over time. 


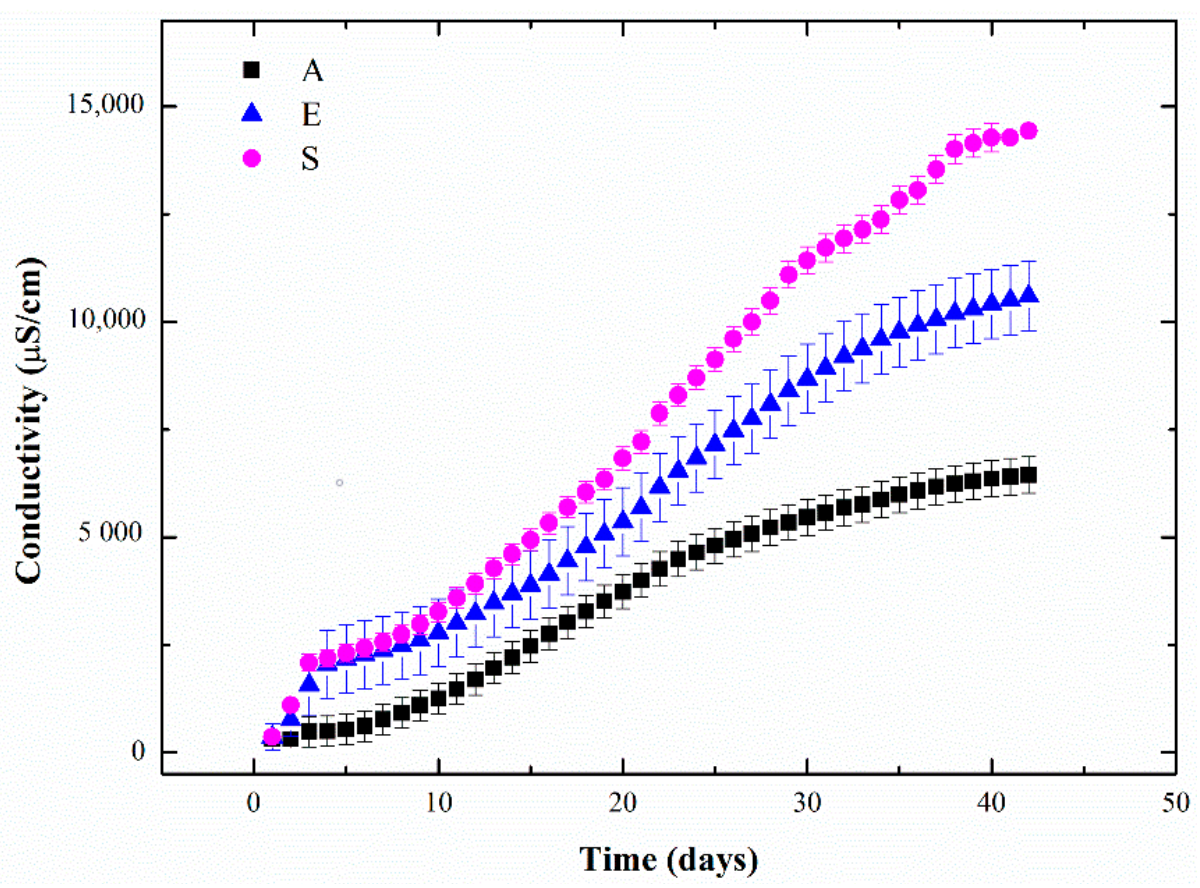

Figure 5. Micronutrient release study of the different matrices in soil: accumulation of conductivity in leachates with time.

This kinetics can be beneficial for crops, since zinc is essential for the formation of the internodes of the plants and, for their growth, requiring a greater amount the first days of cultivation, where the plants spend their greatest amount of energy to grow and a lower amount at the end when they are forming the fruits [12].

The profiles obtained for the matrices processed by protocols $\mathrm{A}$ and $\mathrm{E}$ are similar the first 20 days had the same slope, although the values of matrix $E$ were higher and this matrix releases more nutrients from day 20 . This is due to the fact that both released zinc at the same rate, although matrix E, having a greater amount of zinc, presented a higher release. Matrix E presents lower water uptake capacity, which prevents it from releasing the zinc quickly. On the other hand, the profile obtained for the matrix processed by protocol $\mathrm{S}$ changed, having a steeper slope and, therefore, a faster release. This behavior could be due to the distribution of zinc in this matrix, as already mentioned before, and the higher water uptake capacity presents in this matrix. In this way, as the micronutrient was more superficial in the matrix, it was released more quickly with respect to the other matrices. However, all the matrices had a release that extended to approximately 40 days of use. For this reason, it is considered that they are ideal for crops with a growth similar to that of lettuce, peppers and zucchini, which are usually harvested after 40-50 days of cultivation.

\subsubsection{Matrix Biodegradability}

Figure 6 shows the macroscopic aspect of the matrices during the biodegradability study. According to the images, the matrices seemed not to deteriorate until after 10-20 days, when they began to change their color and broke when they were unearthed. The matrices processed by protocols $\mathrm{A}$ and $\mathrm{S}$ seemed to have the same behavior during their biodegradability (maximum time approximately 30 days), while the matrix processed by protocol $\mathrm{E}$ had a longer decomposition time (approximately 40 days). 


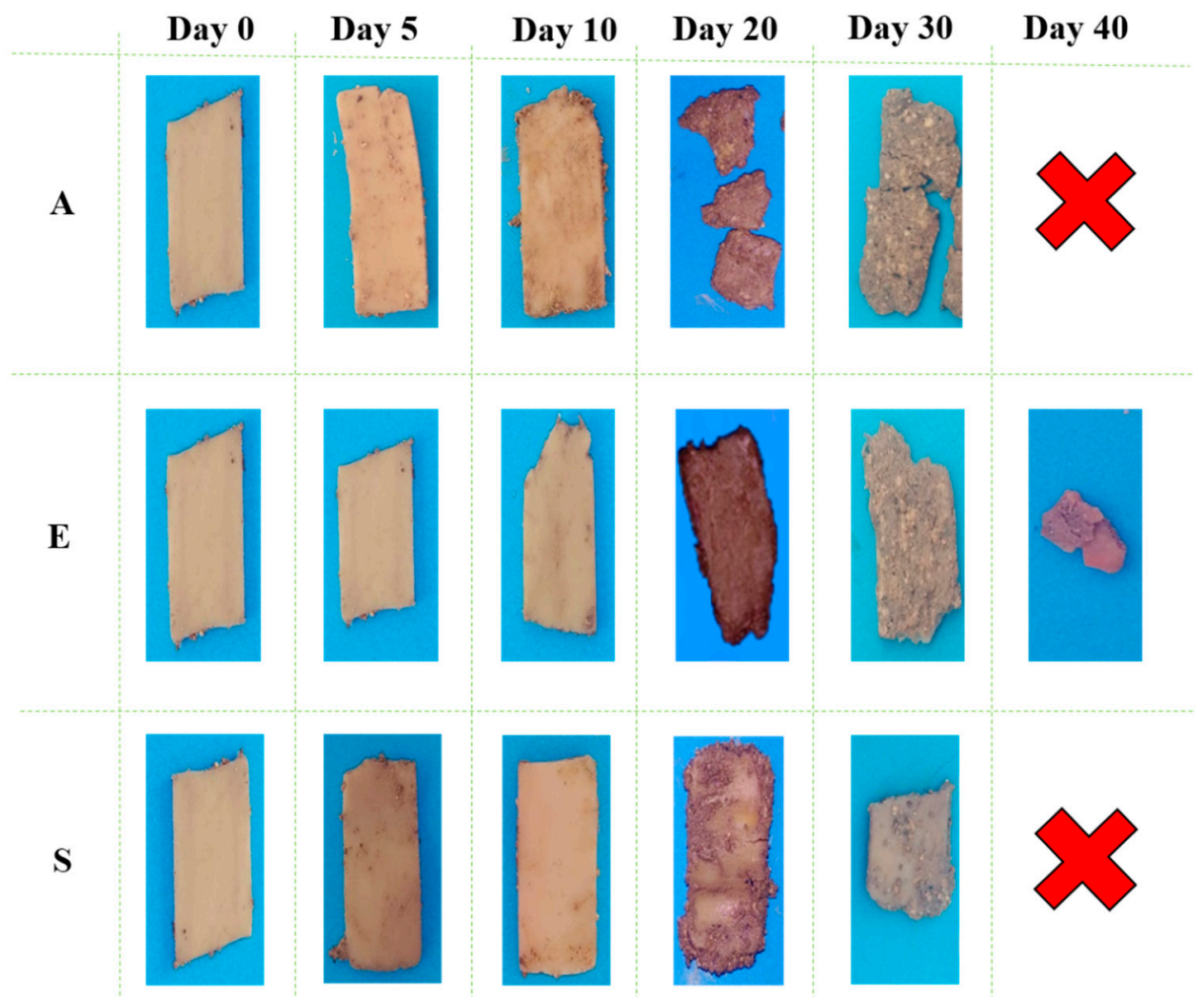

Figure 6. Images of the different matrices at different times in the biodegradation study. Note: The width of samples in day 0 is $10 \mathrm{~cm}$, the other images were obtained at the same focus from the camara.

This behavior could explain the release kinetics that took place. During the first 10 days of cultivation, the matrices maintained their physical integrity, releasing only the micronutrient that the water could transfer out of the matrix. This drag is greater when there is a larger amount of micronutrient at the surface of the matrix, which explains the higher speed of matrix $S$ at this stage. Then, the micronutrient that is released is the one that is bound to the biopolymeric chains. This is the reason why it takes longer to be released, since it requires a certain degree of biodegradation of the matrix. In addition, it can be observed that the matrix took the same time to degrade as it did to release all the micronutrient, which shows that the zinc release depends on the biodegradation of the matrix due to the interactions between zinc ions and matrix chains.

\subsubsection{Crop Evaluation}

Finally, the matrices were tested in real crops to determine the degree of assimilation. Figure 7 shows the lettuces and peppers grown in this analysis. Firstly, differences were observed between the different cultivated lettuces $(\mathrm{L})$ and peppers $(\mathrm{P})$. Depending on the amount of zinc incorporated, the plants had a more homogeneous appearance or not. The crops of the negative control (-) as well as those that had the matrices processed by protocols A and S incorporated, had certain defects, such as deformed leaves, brown spots and shorter roots. However, these defects were not found in the crops of the positive control (+) and those that had the matrix processed by protocol E incorporated. These differences were also seen in the height of the plant, dimensions of the leaves and total foliage of the crop (Table 5). In this way, the matrices processed by protocol E were the most efficient, producing larger plants with more leaves, showing better results than even when conventional fertilization is used (positive control). On the other hand, the matrix processed by protocol A did not generate great differences with respect to the negative control, indicating that its incorporation as fertilizer is not beneficial. The matrix processed by protocol $\mathrm{S}$ showed an interesting behavior, with results similar to those of the matrix 
processed by protocol $\mathrm{E}$ when used on lettuce but also similar to those of the negative control when used on pepper. This behavior is due to the rapid growth of the crop. In this way, as lettuce grows faster, the faster release of zinc from the matrix processed by protocol $\mathrm{S}$ is not reflected in the product of this crop. However, as pepper grows more slowly, there comes a time when it has not finished growing yet but the matrix has released most of the micronutrient, generating an excess of zinc in the plant at the beginning of the growth and a deficit of zinc in the last days of growth.

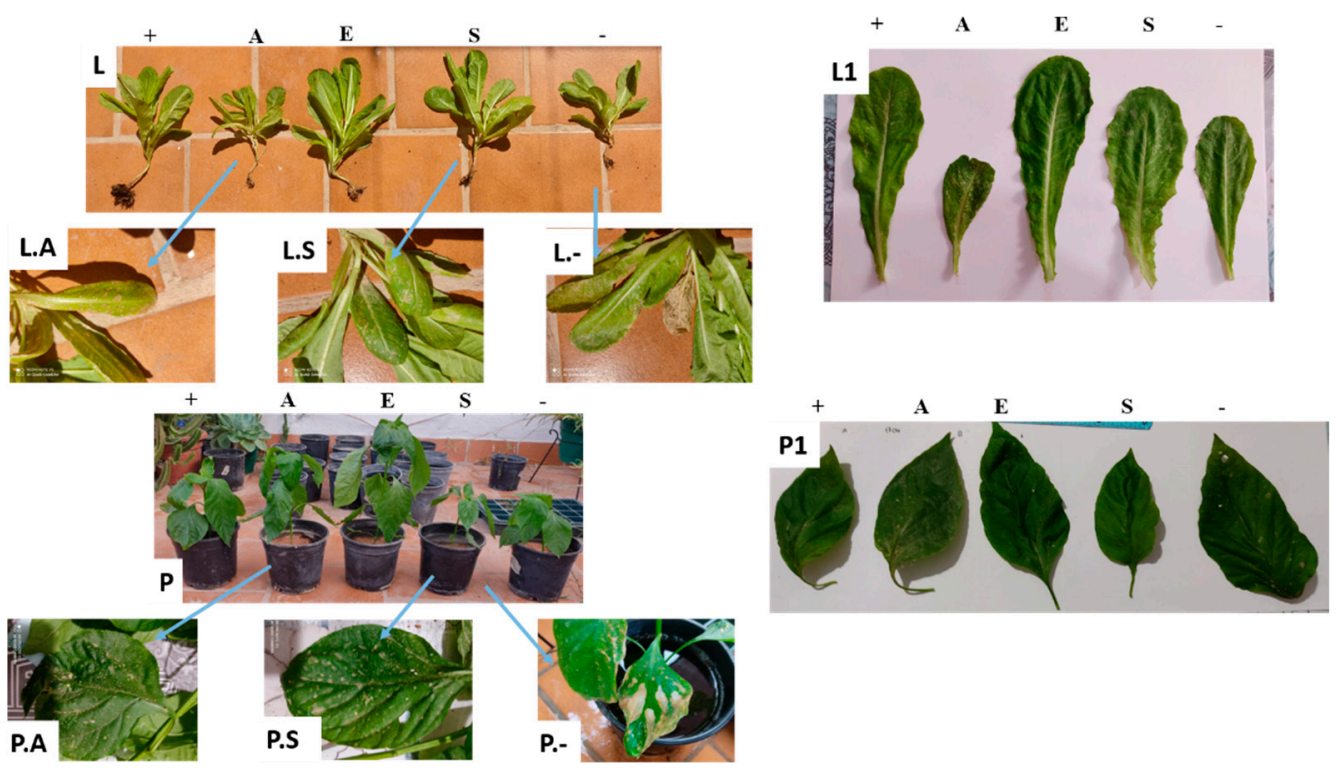

Figure 7. Photographs of lettuces $(\mathrm{L})$ and peppers $(\mathrm{P})$ fertilized with the different matrices $(\mathrm{A}, \mathrm{E}, \mathrm{S})$, by conventional fertilization (+) or without fertilization (-). L.-, L.A, L.S, P.-, P.A and P.S: detailed pictures of visual deficiencies. L1 and P1: comparison of the largest leaves of each crop.

Table 5. Characteristics of crops fertilized with the different matrices (A, E, S), by conventional fertilization (+) or without fertilization (-). Different letters and roman numerals mean significant differences.

\begin{tabular}{|c|c|c|c|c|c|c|c|c|}
\hline \multirow[b]{3}{*}{ Protocol } & \multicolumn{4}{|c|}{ Lettuce } & \multicolumn{4}{|c|}{ Italian Sweet Pepper } \\
\hline & \multirow[b]{2}{*}{$\begin{array}{l}\text { Height } \\
\text { (cm) }\end{array}$} & \multicolumn{2}{|c|}{ Foliage } & \multirow{2}{*}{$\begin{array}{c}\mathrm{Zn} \\
\text { Content } \\
\text { (ppm) }\end{array}$} & \multirow[b]{2}{*}{$\begin{array}{l}\text { Height } \\
\text { (cm) }\end{array}$} & \multicolumn{2}{|c|}{ Foliage } & \multirow{2}{*}{$\begin{array}{c}\text { Zn } \\
\text { Conten } \\
\text { (ppm) }\end{array}$} \\
\hline & & $\begin{array}{c}\text { Size } \\
(\mathrm{h} \times \mathrm{w}) \mathrm{cm}\end{array}$ & $\begin{array}{l}\text { Number of } \\
\text { Leaves }\end{array}$ & & & $\begin{array}{c}\text { Size } \\
(h \times w) ~ c m ~\end{array}$ & $\begin{array}{l}\text { Number of } \\
\text { Leaves }\end{array}$ & \\
\hline+ & $26^{a}$ & $11.2 \times 3.4^{\mathrm{A}}$ & $11^{\mathrm{I}}$ & 70.1 & $30^{a}$ & $19.6 \times 9.7^{\mathrm{A}}$ & $15^{\mathrm{I}}$ & 29.7 \\
\hline A & $20^{b}$ & $8.4 \times 3.3^{\mathrm{B}}$ & $8^{\mathrm{II}}$ & 32.7 & $36^{b}$ & $16.4 \times 9.0^{\mathrm{B}}$ & $14^{\mathrm{I}}$ & 16.7 \\
\hline $\mathrm{E}$ & $28^{a}$ & $15.5 \times 5.7^{C}$ & $14^{\mathrm{III}}$ & 155.3 & $42^{c}$ & $19.1 \times 9.4^{\mathrm{A}}$ & $15^{\mathrm{I}}$ & 71.0 \\
\hline$S$ & $25^{\mathrm{a}}$ & $13.1 \times 5.2^{\mathrm{D}}$ & $14^{\mathrm{III}}$ & 94.4 & $28^{a}$ & $13.2 \times 7.5^{C}$ & $9^{\text {II }}$ & 51.6 \\
\hline- & $19^{b}$ & $12.6 \times 5.2^{\mathrm{D}}$ & $6^{\mathrm{II}}$ & 28.8 & $30^{\mathrm{a}}$ & $14.5 \times 7.5^{\mathrm{C}}$ & $8^{\mathrm{II}}$ & 13.5 \\
\hline
\end{tabular}

Regarding the amount of zinc assimilated by each plant, both the lettuce and pepper crops that were subjected to fertilization with the matrix processed with protocol $\mathrm{E}$ were the ones that retained the largest amount of zinc, surpassing conventional fertilization (positive control). It is worth mentioning that this value did not reach toxicity $(<200 \mathrm{ppm})$, which would cause food poisoning [47]. This could increase the value of these vegetables, making this method of fertilization even more efficient. The matrix processed by protocol $\mathrm{S}$ also exceeded the assimilation values of conventional fertilization, corroborating the efficiency of the controlled release of micronutrients in the crops, although it did not reach the values reached by matrix E. On the other hand, the matrix processed by protocol A, although it improved the amount of zinc in the plant compared to the negative control (without fertilization), it did not reach the expected values after fertilization. This is due 
to the low amount of zinc that the matrix retained. It is also worth mentioning that the matrices processed by protocols E and S contained sulfur (sulfate ions), which counteracted the $\mathrm{pH}$ of the soil, as previously mentioned, preventing the calcification of the plants [27], which did not occur with the matrix processed by protocol A.

The germination studies determined that the matrices did not pose any problems for the correct germination of the seeds, thus they can be incorporated from the sowing of the crop, lightening the process. In addition, the water capacity of the soil increased from ca. 26 to $43 \%$ when the matrices were incorporated. This is due to the fact that the water uptake capacity of the matrices, although low, allowed irrigation water to be retained and used more effectively in the crops as an additional water source. This reduced the frequency of irrigation by approximately 33\%.

\section{Conclusions}

To sum up, it has been possible to develop soy protein-based matrices with adequate zinc retention and distribution by incorporating an immersion stage with ethanol in this process. In addition, these matrices presented sustainable mechanical properties and can release the zinc in a controlled way. During cultivation, these matrices have provided the necessary zinc for the correct development of lettuce and peppers in zinc-deficient soils, even improving the efficiency of conventional fertilizers. They also made possible to reduce their irrigation. All this leads to better developed and more nutritious crops, using fewer resources (lowering prices). This work has opened a new possibility of creating more efficient devices for the incorporation of fertilizers to crops, which produce excellent results in crops and have an affordable price for industrial use. As future perspective, it would be important to evaluate their behavior with other micronutrients and even combinations of them to expand their usefulness.

\section{Patents}

Jiménez Rosado, Mercedes, Perez Puyana, Víctor Manuel, Romero García, Alberto, Guerrero Conejo, Antonio: Matrices proteicas de soja para la liberación controlada de agua y micronutrientes para cultivos y su método de preparación. Invention Patent, Intellectual Property. Application: 2020-11-13.

Supplementary Materials: The following are available online at https://www.mdpi.com/2073 $-4395 / 11 / 3 / 580 / s 1$, Figure S1: Scheme of the experimental set-up used for the zinc release in soil measurements.

Author Contributions: Conceptualization, M.J.-R., V.P.-P. and A.R.; methodology, M.J.-R.; validation, V.P.-P. and A.R.; formal analysis, M.J.-R.; investigation, M.J.-R.; resources, A.G.; data curation, M.J.-R. and V.P.-P.; Writing-Original draft preparation, M.J.-R. and V.P.-P.; Writing-Review and editing, A.R.; visualization, V.P.-P.; supervision, A.R. and A.G.; project administration, A.R.; funding acquisition, A.G. All authors have read and agreed to the published version of the manuscript.

Funding: This study was financially supported by the "FEDER/Ministerio de Ciencia e InnovaciónAgencia Estatal de Investigación", through the project RTI2018-097100-B-C21 and The APC was funded by MDPI.

Institutional Review Board Statement: Not applicable.

Informed Consent Statement: Not applicable.

Data Availability Statement: The data presented in this study are available on request from the corresponding author.

Acknowledgments: The authors acknowledge the "Ministerio de Educación y Formación Profesional" for the M. Jiménez-Rosado (FPU2017/01718). The authors also thank CITIUS for granting access to and their assistance with the microscopy and microanalysis services.

Conflicts of Interest: The authors declare no conflict of interest. 


\section{References}

1. Organización de las Naciones Unidas para la Alimentación y la Agricultura Cultivos. Available online: http:/ /www.fao.org/ faostat/es/\#data/QC/visualize (accessed on 27 April 2020).

2. Saïdou, A.; Kuyper, T.W.; Kossou, D.K.; Tossou, R.; Richards, P. Sustainable soil fertility management in Benin: Learning from farmers. NJAS Wageningen J. Life Sci. 2004, 52, 349-369. [CrossRef]

3. Scherr, S.J. Soil Degradation: A Threat to Developing-Country Food Security by 2020? International Food Policy Research Institute: Washington, DC, USA, 2020.

4. Fertilizar: Civil Association Use of Fertilizers in 2019. Available online: https://www.fertilizar.org.ar/ (accessed on 17 August 2020).

5. Hignett, T.P. Fertilizer Manual; Springer Science \& Business Media: London, UK, 2013; ISBN 9789401715386.

6. Flinck, A. Fertilizers and Fertilization: Introduction and Practical Guide to Crop Fertilization; Verlag Hemie: Weinheim, Germany, 1982; ISBN 3527258914.

7. Kondraju, T.T.; Rajan, K.S. Excessive fertilizer usage drives agriculture growth but depletes water quality. ISPRS Ann. Photogramm. Remote Sens. Spat. Inf. Sci. 2019, IV-3/W1, 17-23. [CrossRef]

8. Agencia de Gestión Agraria y Pesquera de Andalucía. Caracterización del Sector Agrario y Pesquero de Andalucía; Consejería de Agricultura, Ganadería, Pesca y Desarrollo Sostenible de la Junta de Andalucía: Sevilla, Spain, 2019.

9. Junta de Andalucía Exportaciones e Importaciones Agroalimentarias. Available online: https://www.juntadeandalucia. es/organismos/agriculturaganaderiapescaydesarrollosostenible/servicios/estadistica-cartografia/estadisticas-agricolas/ paginas / comercio-exterior-agricola.html (accessed on 24 October 2020).

10. Galdeano, E. Economic impact of the quality and environmental actions on the value added in horticultural cooperatives of Andalusia. In Proceedings of the 24th International Congress of CIRIEC; CIRIEC: Milano, Italy, 2002.

11. Peña, A.; Gálvez, A.; Rodríguez-Liébana, J.A.; Jiménez de Cisneros, C.; López Galindo, A.; Viseras, C.; Caballero, E. Adsorption of nutrients on natural Spanish clays for enriching seed coatings. Adsorption 2017, 23, 821-829. [CrossRef]

12. Broadley, M.R.; White, P.J.; Hammond, J.P.; Zelko, I.; Lux, A. Zinc in plants: Tansley review. New Phytol. 2007, 173, 677-702. [CrossRef] [PubMed]

13. Silva, J.; Uchida, R. Essential Nutrients for Plant Growth. In Plant Nutrition Management in Hawaii's Soils, Approaches and Application to Tropical and Subtropical Agriculture; CTAHR Editorial: Honolulu, HI, USA, 2000; ISBN 978-1-929325-08-5.

14. Hernández, T.; Chocano, C.; Moreno, J.-L.; García, C. Use of compost as an alternative to conventional inorganic fertilizers in intensive lettuce (Lactuca sativa L.) crops-Effects on soil and plant. Soil Tillage Res. 2016, 160, 14-22. [CrossRef]

15. Pagnani, G.; Pellegrini, M.; Galieni, A.; D’Egidio, S.; Matteucci, F.; Ricci, A.; Stagnari, F.; Sergi, M.; Lo Sterzo, C.; Pisante, M.; et al. Plant growth-promoting rhizobacteria (PGPR) in Cannabis sativa 'Finola' cultivation: An alternative fertilization strategy to improve plant growth and quality characteristics. Ind. Crops Prod. 2018, 123, 75-83. [CrossRef]

16. Shaji, H.; Chandran, V.; Mathew, L. Organic fertilizers as a route to controlled release of nutrients. In Controlled Release Fertilizers for Sustainable Agriculture; Elsevier: Amsterdam, The Netherlands, 2021; pp. 231-245. ISBN 978-0-12-819555-0.

17. Chen, J.; Fan, X.; Zhang, L.; Chen, X.; Sun, S.; Sun, R. Research Progress in Lignin-Based Slow/Controlled Release Fertilizer. ChemSusChem 2020, 13, 4356-4366. [CrossRef] [PubMed]

18. Rakhimol, K.R.; Thomas, S.; Kalarikkal, N.; Jayachandran, K. Nanotechnology in controlled-release fertilizers. In Nanotechnology in controlled-release fertilizers. In Controlled Release Fertilizers for Sustainable Agriculture; Elsevier: Amsterdam, The Netherlands, 2021; pp. 169-181.

19. Merino, D.; Gutiérrez, T.J.; Alvarez, V.A. Potential Agricultural Mulch Films Based on Native and Phosphorylated Corn Starch With and Without Surface Functionalization with Chitosan. J. Polym. Environ. 2019, 27, 97-105. [CrossRef]

20. Mesias, V.S.; Agu, A.B.; Benablo, P.J.; Chen, C.-H.; Penaloza, D.J. Coated NPK Fertilizer Based on Citric Acid-Crosslinked Chitosan/Alginate Encapsulant. J. Ecol. Eng. 2019, 20, 1-12. [CrossRef]

21. Kartini, I.; Lumbantobing, E.T.; Suyanta, S.; Sutarno, S.; Adnan, R. Bioplastic Composite of Carboxymethyl Cellulose/N-P-K Fertilizer. Key Eng. Mater. 2020, 840, 156-161. [CrossRef]

22. Fernández-Espada, L.; Bengoechea, C.; Cordobés, F.; Guerrero, A. Protein/glycerol blends and injection-molded bioplastic matrices: Soybean versus egg albumen. J. Appl. Polym. Sci. 2016, 133, 42980. [CrossRef]

23. De Corato, U.; De Bari, I.; Viola, E.; Pugliese, M. Assessing the main opportunities of integrated biorefining from agro-bioenergy $\mathrm{co} /$ by-products and agroindustrial residues into high-value added products associated to some emerging markets: A review. Renew. Sustain. Energy Rev. 2018, 88, 326-346. [CrossRef]

24. Gontard, N.; Sonesson, U.; Birkved, M.; Majone, M.; Bolzonella, D.; Celli, A.; Angellier-Coussy, H.; Jang, G.-W.; Verniquet, A.; Broeze, J.; et al. A research challenge vision regarding management of agricultural waste in a circular bio-based economy. Crit. Rev. Environ. Sci. Technol. 2018, 48, 614-654. [CrossRef]

25. Jiménez-Rosado, M.; Pérez-Puyana, V.; Cordobés, F.; Romero, A.; Guerrero, A. Development of soy protein-based matrices containing zinc as micronutrient for horticulture. Ind. Crops Prod. 2018, 121, 345-351. [CrossRef]

26. Alloway, B.J. Zinc in Soils and Crop Nutrition, 2nd ed.; IZA and IFA: Brussels, Belgium, 2008.

27. Hibbard, P.L. Sulfur for neutralizinc alkali soil. Soil Sci. 1921, 11, 385-388. [CrossRef]

28. Machado, R.; Serralheiro, R. Soil Salinity: Effect on Vegetable Crop Growth. Management Practices to Prevent and Mitigate Soil Salinization. Horticulturae 2017, 3, 30. [CrossRef] 
29. Alloway, B.J. Soil factors associated with zinc deficiency in crops and humans. Environ. Geochem. Health 2009, 31, 537-548. [CrossRef] [PubMed]

30. Tóth, G.; Hermann, T.; Da Silva, M.R.; Montanarella, L. Heavy metals in agricultural soils of the European Union with implications for food safety. Environ. Int. 2016, 88, 299-309. [CrossRef]

31. Liebens, J. Spreadsheet macro to determine USDA soil textural subclasses. Commun. Soil Sci. Plant Anal. 2001, 32, 255-265. [CrossRef]

32. Jiménez-Rosado, M.; Perez-Puyana, V.; Rubio-Valle, J.F.; Guerrero, A.; Romero, A. Processing of biodegradable and multifunctional protein-based polymer materials for the potential controlled release of zinc and water in horticulture. J. Appl. Polym. Sci. 2020, 49419. [CrossRef]

33. Cong, Z.; Yazhen, S.; Changwen, D.; Jianmin, Z.; Huoyan, W.; Xiaoqin, C. Evaluation of Waterborne Coating for Controlled-Release Fertilizer Using Wurster Fluidized Bed. Ind. Eng. Chem. Res. 2010, 49, 9644-9647. [CrossRef]

34. Essawy, H.A.; Ghazy, M.B.M.; El-Hai, F.A.; Mohamed, M.F. Superabsorbent hydrogels via graft polymerization of acrylic acid from chitosan-cellulose hybrid and their potential in controlled release of soil nutrients. Int. J. Biol. Macromol. 2016, 89, 144-151. [CrossRef] [PubMed]

35. ASTM D570-98: Standard Test Method for Water Absorption of Plastics 2005. Available online: https://www.astm.org/ Standards/D570 (accessed on 19 March 2021).

36. Jiménez-Rosado, M.; Martín, A.; Alonso-González, M.; Guerrero, A.; Romero, A. Nanotechnology in controlled-release fertilizers. In Controlled Release Fertilizers for Sustainable, Agriculture. Polym. Eng. Sci. 2020, pen.25471. [CrossRef]

37. Jiménez-Rosado, M.; Perez-Puyana, V.; Rubio-Valle, J.F.; Guerrero, A.; Romero, A. Evaluation of Superabsorbent Capacity of Soy Protein-Based Bioplastic Matrices with Incorporated Fertilizer for Crops. J. Polym. Environ. 2020. [CrossRef]

38. Torreggiani, A.; Domènech, J.; Atrian, S.; Capdevila, M.; Tinti, A. Raman study of in vivo synthesized Zn(II)-metallothionein complexes: Structural insight into metal clusters and protein folding. Biopolymers 2008, 89, 1114-1124. [CrossRef] [PubMed]

39. Seidell, A.; Linke, W.F. Solubilities of Inorganic and Metal Organic Compounds; A Compilation of Quantitative Solubilirty Data from the Periodical Literature; D. Van Nostrand Company: New York, NY, USA, 1940.

40. Huang, X.; Brazel, C.S. On the importance and mechanisms of burst release in matrix-controlled drug delivery systems. J. Control. Release 2001, 73, 121-136. [CrossRef]

41. Lee, P.I. Initial concentration distribution as a mechanism for regulating drug release from diffusion controlled and surface erosion controlled matrix systems. J. Control. Release 1986, 4, 1-7. [CrossRef]

42. Ma, Z.; Li, Q.; Yue, Q.; Gao, B.; Xu, X.; Zhong, Q. Synthesis and characterization of a novel super-absorbent based on wheat straw. Bioresour. Technol. 2011, 102, 2853-2858. [CrossRef]

43. Montesano, F.F.; Parente, A.; Santamaria, P.; Sannino, A.; Serio, F. Biodegradable Superabsorbent Hydrogel IncreasesWater Retention Properties of Growing Media and Plant Growth. Agric. Agric. Sci. Procedia 2015, 4, 451-458. [CrossRef]

44. Sadeghi, M.; Hosseinzadeh, H. Synthesis of Starch-Poly(Sodium Acrylate-co-Acrylamide) Superabsorbent Hydrogel with Salt and pH-Responsiveness Properties as a Drug Delivery System. J. Bioact. Compat. Polym. 2008, 23, 381-404. [CrossRef]

45. Cuadri, A.A.; Bengoechea, C.; Romero, A.; Guerrero, A. A natural-based polymeric hydrogel based on functionalized soy protein. Eur. Polym. J. 2016, 85, 164-174. [CrossRef]

46. Álvarez-Castillo, E.; Bengoechea, C.; Guerrero, A. Composites from by-products of the food industry for the development of superabsorbent biomaterials. Food Bioprod. Process. 2020, 119, 296-305. [CrossRef]

47. Fosmire, G.J. Zinc toxicity. Am. J. Clin. Nutr. 1990, 51, 225-227. [CrossRef] [PubMed] 